\title{
Situated learning makes easy learning for the biomedical engineering students in blood physiology
}

\section{Lin-lin Wang}

Zhejiang University School of Medicine

Mingzhi Zheng

Hangzhou Medical College

Jin-jie Zhong

Zhejiang University School of Medicine

Ying-ying Chen ( $\nabla$ bchenyy@zju.edu.cn)

Zhejiang University School of Medicine

\section{Research Article}

Keywords: Situated learning; Blood physiology; Undergraduate

Posted Date: April 6th, 2021

DOI: https://doi.org/10.21203/rs.3.rs-356961/v1

License: @ (i) This work is licensed under a Creative Commons Attribution 4.0 International License. Read Full License 
1 Title: Situated learning makes easy learning for the biomedical engineering students in

2 blood physiology

3 Running title: Situated learning improves learning in blood physiology

4 Lin-lin Wang ${ }^{1}$, Mingzhi Zheng ${ }^{2}$, Jin-jie Zhong ${ }^{3}$, Ying-ying Chen ${ }^{3 *}$

5

$6{ }^{1}$ Department of Basic Medicine Sciences, and Department of Orthopaedics of Sir Run

7 Run Shaw Hospital, Zhejiang University School of Medicine, Hangzhou 310058, China.

$8 \quad{ }^{2}$ Department of pharmacology, Hangzhou medical college, Hangzhou 310053, China.

$9{ }^{3}$ Department of Basic Medicine Sciences, and Department of Obstetrics of the Second

10 Affiliated Hospital, Zhejiang University School of Medicine, Hangzhou 310058, China

11

12

13

*Corresponding author at:

Ying-ying Chen, $\mathrm{PhD}$

Department of Basic Medicine Sciences, Zhejiang University School of Medicine, Hangzhou 310058, China;

E-mail address: bchenyy@zju.edu.cn

Tel and Fax: 0086-571-88208250

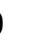

1




\section{Abstract}

\section{Background}

Blood physiology is difficult to be understood and remembered for biomedical engineering students by traditional teaching method. In this study, we aim to know whether situated learning was helpful for students learning the key points of theoretical knowledge in blood physiology.

\section{Methods}

In the study group (2019), 51 sophomores were randomly divided into two smaller teams. Team A was provided with the script of wisdom tooth extraction, which contains the knowledge of hemostasis and coagulation. Team B was provided with a script of rescue in the intensive care unit, which contains the knowledge of blood type and blood transfusion. In the control group(2018), 52 sophomores participated in traditional lectures given by the teacher with the aid of PowerPoint slides. After class, students from both groups completed the theoretical test, and their test scores were compared. In addition, we designed a questionnaire to get feedback from the study group.

\section{Results}

The theoretical test showed the scores in the study group were higher than those in the control group(2018). The questionnaire analysis showed the positive role of situated learning in learning the key points.

\section{Conclusions}

To sum up, situated learning makes easy learning for undergraduate in blood physiology. 


\section{Background}

Physiology is a medical professional course offered by our school for biomedical engineering students. The original purpose of this course is to help students to better understand the concept of a "combination of medicine and engineering" and to establish a solid medical foundation. Blood physiology involves lots of knowledge, including hemostasis, coagulation, blood type, and blood transfusion, which are the key points of learning but also are difficult to be understood and remembered. Moreover, for those engineering students without a medical background, it is a quite difficult task to quickly grasp this knowledge in a short period of time. Lave and Wenger's situated learning theory opened new territory by illuminating social and cultural learning processes[1]. Situated learning is centered on the learner, and the learner is placed in the teaching situation. Situated learning used scenario which simulated essential aspects of a medical situation so that a student can consolidate learning in a safe and secure environment[2]. The clinical situation is a component of the simulation typology that uses a prewritten scenario, which has been proved to enhance basic knowledge learning in many medical courses[3-5].

Few studies discussed the effect of applying simulated teaching program to physiology course, for example, blood physiology. Therefore, it is important to know about whether situated learning could make biomedical engineering students easy earning of blood physiology. Therefore, we attempted to create a simulated teaching program for biomedical engineering students. 51 sophomores who participated in the situated learning in 2019 were taken as the study group. 52 sophomores who only participated in traditional lectures in 2018, during which the same teacher gave lectures with the aid of PowerPoint slides, were taken as the control group. After class, students from both groups completed the theoretical test, and their test scores were compared. In addition, we designed a questionnaire to get feedback from the study group. 


\section{Methods}

\section{Intervention design and procedures}

Institutional approval was obtained before the study was initiated. All methods were carried out in accordance with relevant guidelines and regulations in Zhejiang University. The study involved students from biomedical engineering in the second professional year at Zhejiang University. These biomedical engineering students never had medical courses or training over the past. Students in 2019 received as a study group 2019(n=51), while students in 2018 received traditional teaching as a control group 2018(n=52). Students in both groups came from the same specialty and had taken the same professional courses before. All students agreed to participate in the study. Meanwhile, the teaching team consisted of an associate teacher and one assistant from senior classes. During our class, the teacher supervised the overall process and the theoretical knowledge involved, while one assistant helped to coordinate the performance order. The overall study process is shown in Figure 1. The design and approach of situated learning are shown in Table 1.

Study group 2019 was further randomized and divided into two smaller teams by picking numbered lots. Team A was provided with the script of wisdom tooth extraction, which contains the knowledge of hemostasis, coagulation. Team B was provided with a script of rescue in the intensive care unit, which contains the knowledge of blood type, and blood transfusion. Each team was asked to study the script and prepared for the performance for 2 weeks, after which they were required to role play in the class to mimic the clinical situation in $20 \mathrm{~min}$. After the performance by students, the teacher made a short summary and evaluation in $5 \mathrm{~min}$. 


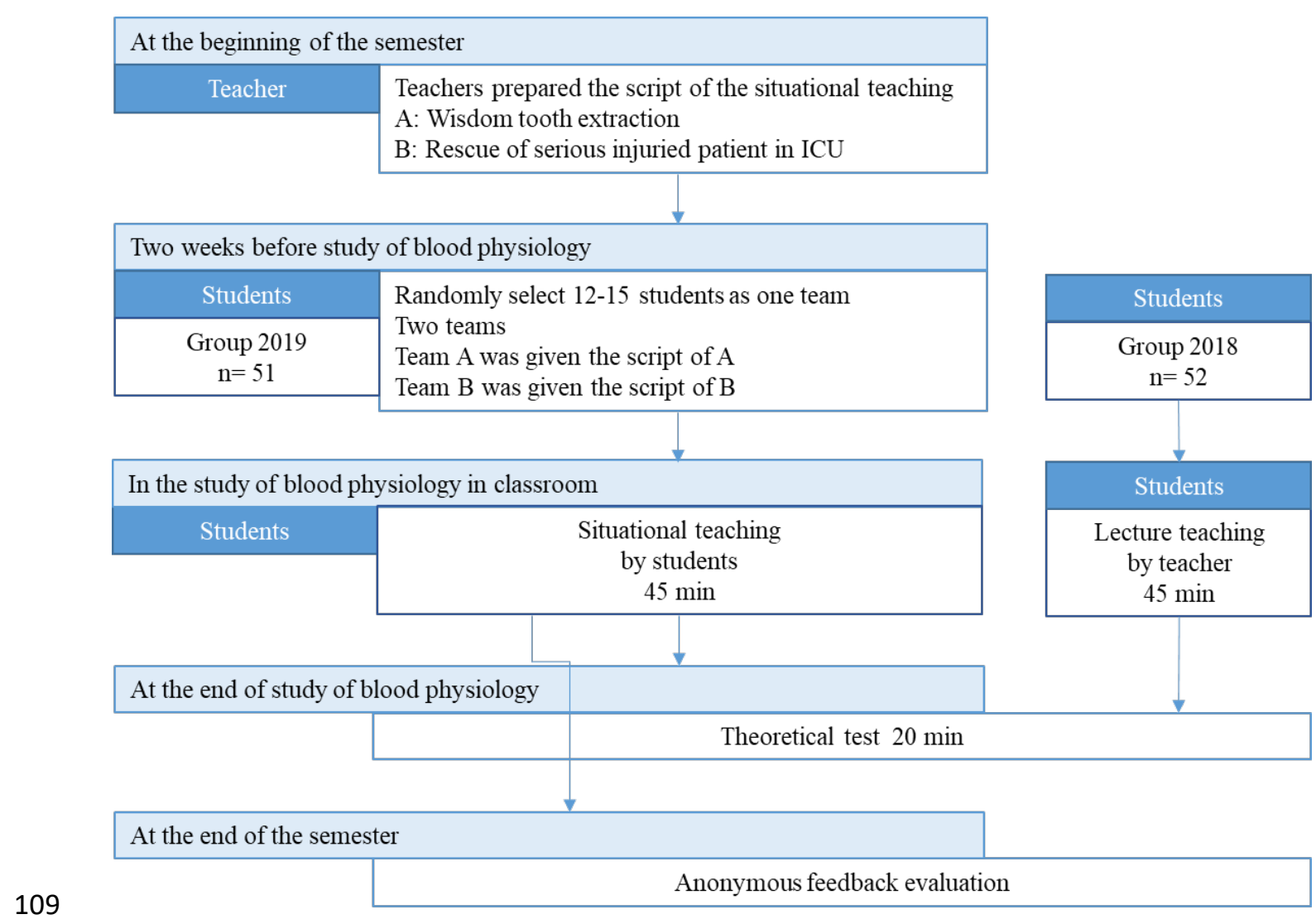

111 Figure 1. The time flow chart of preparing, performing and evaluating of situated 112 learning. 
Table 1 The design and approach of situated learning.

127

design and approach

Situated learning

Team A: Wisdom tooth extraction

Team B: Rescue of serious injuried patient in ICU

Key points of knowledge Hemostasis and blood coagulation

Blood type and blood transfusion

Students in team

(Before class)

1) According to the script, assign roles of 2

doctors, 2 nurses, 1 patient, 2 family members

2) Actors rehearse for presentation

3) Prepare PPT slides, including the key points and expanding knowledge;

4) Search for videos which related to key points, for example, the animation of hemostasis, coagulation, and blood type determination

Students in team

1) Performance

(In class, $20 \mathrm{~min} /$ team)

2) Team members ask and answer questions when they were acting as patients' families members, doctors and nurses

3) The team explains knowledge points through PPT and videos, and answer questions after performance

Students not in team

1) Watch the performance and videos given by

(In class) team members;

2) Listen to the dialogue between doctor and nurse, family member and doctors, family member and nurses 
3) Listen to the interpretation given by team members with PPT slides, videos

4) Ask questions if he does not understand

5) Comment on the presentation

Teacher and assistant

1) Prepare the main script before class

2) Supervise the process in class

3) Make a brief summary before the end of the class in $5 \mathrm{~min}$

4) Prepare theoretical test questions and feedback evaluation after class

\section{Script of situated learning for team A: Wisdom tooth extraction}

131 Key points: Hemostasis and coagulation

132 Place: Stomatological hospital

133 Characters: 2 doctors, 2 nurses, 1 patient, 2 family members

134 Script: Students act as patients, doctors, nurses, and family members. Students act as doctors and nurses were wearing white coats. Students simulated the process of patients entering a stomatological hospital for wisdom tooth extraction. A student acted as the patient and he wanted to have his wisdom tooth pulled out. He was told by the nurse that he had to do a series of examinations, including clotting time and bleeding time. The family members could not understand why he had to do these examinations. They asked the nurses: (1) what is the clotting time test? (2) What is the bleeding time test? (3) Why these tests were needed to be done before the operation? In the whole process, through the dialogue between nurses and their families, patient, and doctors, the relevant guiding questions and answers are given: (1) The process of physiological hemostasis; (2) The process of blood coagulation; (3) Which factors can affect blood coagulation? After the performance, the team asked questions to the rest student, such as "After the tooth was extracted by the doctor, what kind of treatment should be done 
by the doctor to help the patient to stop bleeding?" "What should the doctor tell the patient to do to avoid subsequent bleeding?"

\section{Script of situated learning for team B: rescue in the intensive care unit}

Key points: Blood type and blood transfusion

Place: The emergency room in the hospital

Characters: 2 doctors, 2 nurses, 1 patient, 2 family members

Script: Students act as patients, doctors, nurses, and family members. Students act as doctors and nurses were wearing white coats. A traffic accident seriously injured patient was sent to the hospital for emergency treatment. Doctor A and two nurses are giving emergency treatment to the patient. Due to excessive blood loss, blood transfusion was needed. The blood type of the patient was A. The family members worried about this patient. They asked the nurses: (1)What was the harm of excessive blood loss? (2)What kind of blood type can be transfused to this patient? (3) The blood type of his sister is A. She asked whether her blood could be transfused to the patient right now? Through the doctor's diagnosis and treatment, the dialogue between doctors, nurses, and the family members, besides the above three questions, the other relevant guiding questions and answers are given: (1) What is blood type? (2) What are the criteria for judging the need for blood transfusion? (3) What principles should be followed during blood transfusion?

\section{Questionnaire and feedback}

To assess the understanding of blood physiology, at the end of the learning of the whole blood physiology, students in both groups were asked to complete a theoretical test in the form of 25-single choice questions in $20 \mathrm{~min}$. The questionnaire was structured to determine cognitively and recall memory knowledge of blood physiology. It also tested the students' conceptual understanding, as it required them to analyze the information 

group 2019.

\section{Results}

195 Total score of blood physiology: 25-single choice questions in blood physiology. Each

In total, 103 participants successfully completed the theoretical test, with 51 and 55 were included in the study and control groups, respectively. The results was shown in Table 2. Group 2019 students achieved a higher total score in blood physiology than group 2018 students $(P<0.01)$. Interestingly, group 2019 students achieved higher scores in questions related to hemostasis and blood coagulation than group 2018 students $(P<0.01)$. Meanwhile, group 2019 students achieved higher scores in questions related to blood type and blood transfusion than group 2018 students $(P<0.01)$.

Table 2 Comparison of the scores of the theoretical test of students in group 2018 and

$$
\text { Group } 2018 \quad \text { Group } 2019
$$

Lecture by teacher by students

\begin{tabular}{lll}
\hline Total score & $74.15 \pm 7.22$ & $83.37 \pm 5.79 * *$ \\
Sub-score A & $21.79 \pm 4.11$ & $25.19 \pm 4.19 * *$ \\
Sub-score B & $23.88 \pm 4.13$ & $28.53 \pm 2.67 * *$ \\
\hline
\end{tabular}


related to hemostasis and blood coagulation(NO.14, 15, 16, 17, 18, 19). Sub-score B 6single choice questions related to blood type and blood transfusion(NO. 20, 21, 22, 23, 24, 25). Data were presented as Mean \pm SD. Data were analyzed and compared using GraphPad Prism 8 software. ${ }^{* *} P<0.01$, t-test, compared with group 2018.

The results of the feedback were shown in Figure 2. The majority of the students in study group showed agreement/strong agreement approved the students' performance and thought that the students' performance was correct(94.12\%). Importantly, the majority of the students in study group showed agreement/strong agreement toward liking situated learning $(88.24 \%)$. There was agreement/strong agreement that situated learning helped them better their conceptual understanding of blood physiology (88.24\%). $92.16 \%$ of students thought situated learning helped them to appreciate the importance of principles of blood transfusion. When asked whether they were likely to use situated learning in future courses or voluntarily recommend its use to next year's students, most students gave a positive response(88.24\%, 88.24\%). Although a very small percentage of students did have a less than enthusiastic approach toward the question 3 and question 5(1.96\%,1.96\%), none of the students reported any strongly disagree regarding the use of situated learning $(0 \%)$.

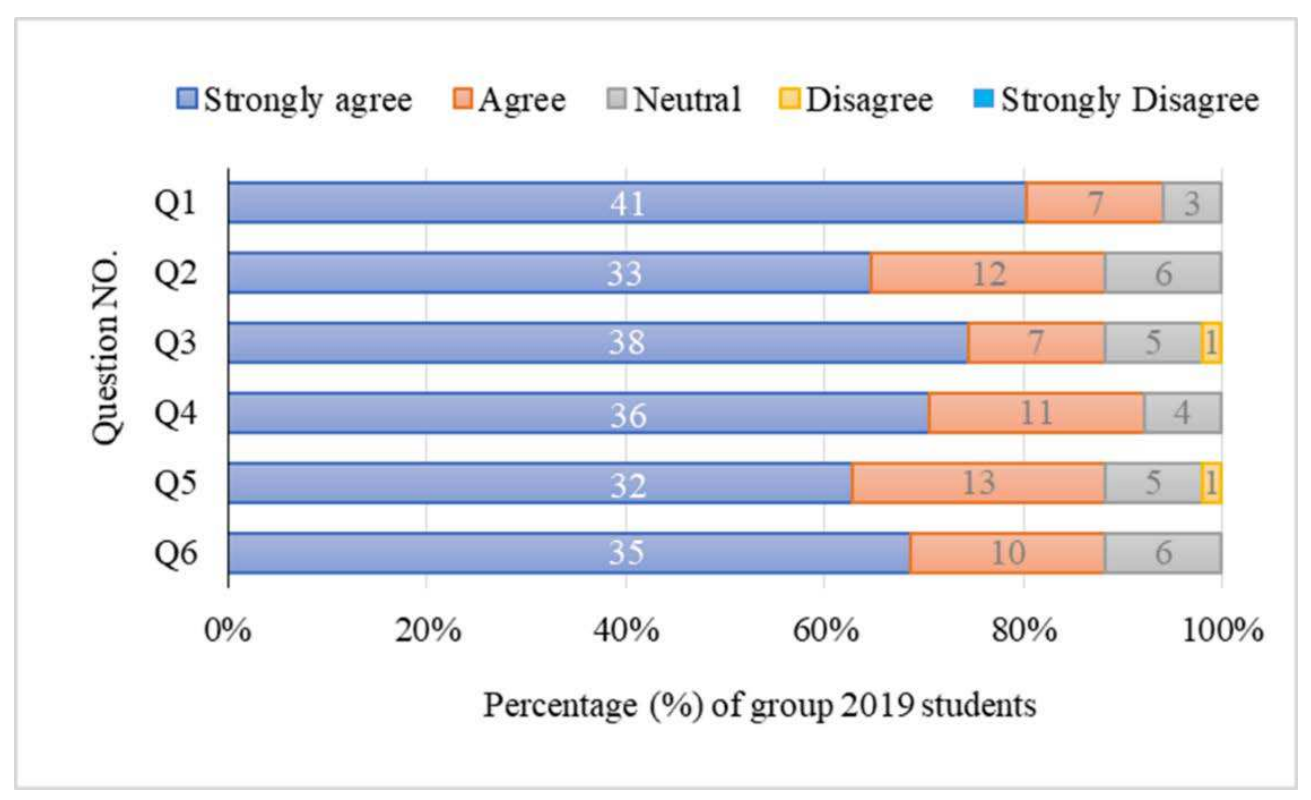

Figure. 2. Student feedback to questions based on Likert scale template. The questions 
are as follows. Q1, The content presented by students in situated learning is correct. Q2, I like the situated learning. Q3, The situated learning helped me understand the blood physiology better. Q4, The situated learning helped me appreciate the importance of principles of blood transfusion. Q5, I hope there will be situated learning in future courses. Q6, I am likely to recommend situated learning to next year's students.

\section{Discussion}

According to 5 years of teaching observation, we found that among the knowledge points in blood physiology, hemostasis, coagulation, blood type and blood transfusion are difficult to be understand and remembered for those bioengineering students with no medical background. In our study, it is interesting to find that the test scores are significantly better than those of the control group, which proves that the situated learning can significantly improve test performance. Situated learning exploration made the students master the basic knowledge and basic application of these key points and difficulties more firmly in blood physiology. Our results was consisted with previous reports in medical education[3-5]. This better performance in our study adds merit to the hypothesis that knowledge acquisition and retention are better while using situated learning in blood physiology.

It is also worth noting that situated learning method was welcomed by the students in study group. As for the students who were not in teams, they felt the topic of situational learning more enjoyable and easier to understand due to inclusion of role play in the classroom. As for the students who were in teams, the creation of group discussion situation is helpful to change the students' learning method of reciting and memorizing by rote. It can improve the students' ability of practice, self-study, thinking and communication, and really integrate theory with practice. Furthermore, in the process of role playing, they will memorize the knowledge by heart. 
We believe that learning is enhanced when the environment seems realistic[6]. Medical simulation replicates medical conditions, such as normal physiology and abnormal pathology. As for the two scripts, we designed them carefully based on the principle as follows: The script should closely mimic the medical condition, which exactly contained the physiological knowledge of key points, so as to stimulate students' interest, attract their attention, and let them experience the value of learning. On the other hand, it should not be very difficult to operate or perform. Thus, they can fully prepared and confident to role play well within two weeks.

This study delivered a practical and useful strategy to teach and learn in physiology course. However, the implementation of situated learning in the basic course of physiology, which have a higher requirement for teachers. Teachers not only have a good understanding of relevant professional knowledge, but also need to better integrate relevant knowledge into the situated learning, for example, script writing and editing. In addition, teachers are required to devote more time and energy to make a lot of preparation, and communication with team members.

There are some limitations in our study. First, we only compared the immediate impact of situated learning and traditional lecture on students' quiz scores. The participation of more students will help to obtain more objective results. Second, more key points of knowledge should have been included for better interpretation. Third, the study was conducted with two different classes across the years. Students had personal preferences on different pedagogical models. The interpersonal variation might have an impact on the effectiveness of situated learning or the traditional lecture. Thus, we believe that implication of situated learning should also be assessed prospectively on the same batch of students in regards to their knowledge, attitude, and practice in upcoming years of the blood physiology courses for reaching a more convincing conclusion. 


\section{Conclusions}

Taken together, situated learning by students themselves enhances student learning, promote active learning and peer collaboration in teams. Situated learning has better acceptability by the students as it is more practically oriented and interesting. Our findings suggest that situated learning makes easy learning for the biomedical engineering students in blood physiology.

\section{Ethics approval and consent to participate}

The World Medical Association Declaration of Helsinki guidance was followed in the study. The study was approved by the Institutional Review Board (IRB) committee of Zhejiang University (Approval No. 2018-Zdjg08058). Informed consent was obtained from all individual participants included in the study.

\section{Consent for publication}

Not applicable.

\section{Availability of data and materials}

The datasets used and/or analysed during the current study available from the corresponding author on reasonable request.

\section{Competing interests}

No conflicts of interest, financial or otherwise, are declared by the authors.

\section{Funding}

This work was supported by the funding of the first batch of teaching reform research projects in the 13th five-year plan of higher education in Zhejiang University(No. 


\section{Authors' contributions}

L.W. and Y.C. conceived and designed research; L.W. and M.Z. performed interpreted results of experiments; M.Z. and J.Z. prepared figures; L.W. and Y.C. drafted, edited, and revised manuscript; Y.C. approved the final version of the manuscript.

\section{Acknowledgments}

Not applicable.

\section{Abbreviations}

Not applicable.

\section{Reference}

1. O'Brien BC, Battista A: Situated learning theory in health professions education research: a scoping review. Adv Health Sci Educ Theory Pract 2020, 25(2):483-509. Kardong-Edgren SE, Starkweather AR, Ward LD: The integration of simulation into a clinical foundations of nursing course: student and faculty perspectives. Int I Nurs Educ Scholarsh 2008, 5:Article26.

3. Quick KK, Blue CM: Using Situated Learning Theory to Build an Interactive Learning

4. Kelly RR, McCrackin MA, Russell DL, Leddy LR, Cray JJ, Larue AC: Teaching Surgical Model Environment to Foster Dental Students' Professionalism: An Ignite Project. J Dent Educ 2019, Development in Research by Using Situated Learning and Instructional Scaffolding. J Am Assoc Lab Anim Sci 2019, 58(3):321-328.

5. Lee KC, Yu CC, Hsieh PL, Li CC, Chao YC: Situated teaching improves empathy learning of the students in a BSN program: A quasi-experimental study. Nurse Educ Today 2018, 64:138-143. 
97(6):1695-1705 .

330 


\section{Figures}

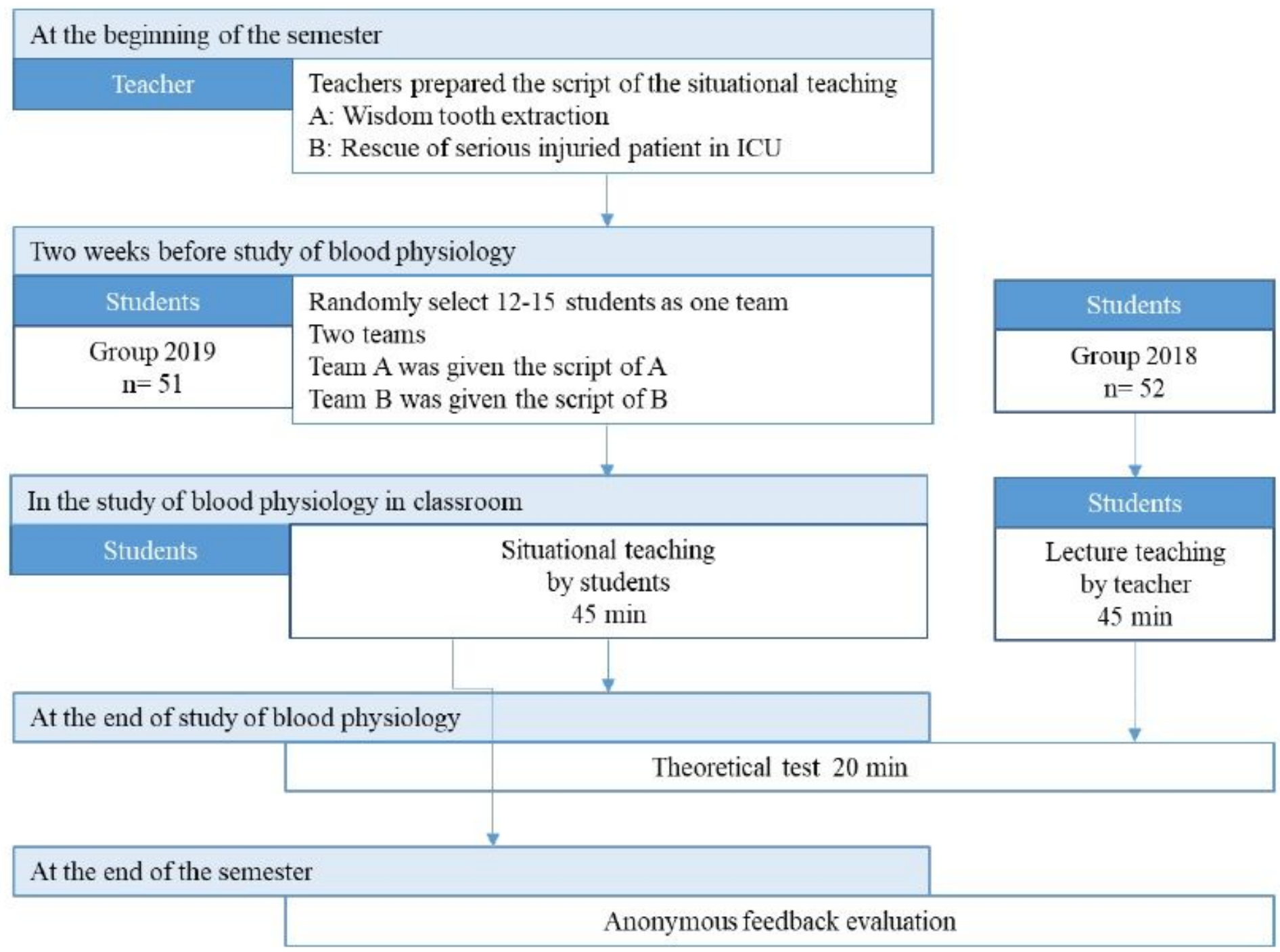

\section{Figure 1}

The time flow chart of preparing, performing and evaluating of situated learning. 
$\square$ Strongly agree $\square$ Agree $\square$ Neutral $\square$ Disagree $\backsim$ Strongly Disagree

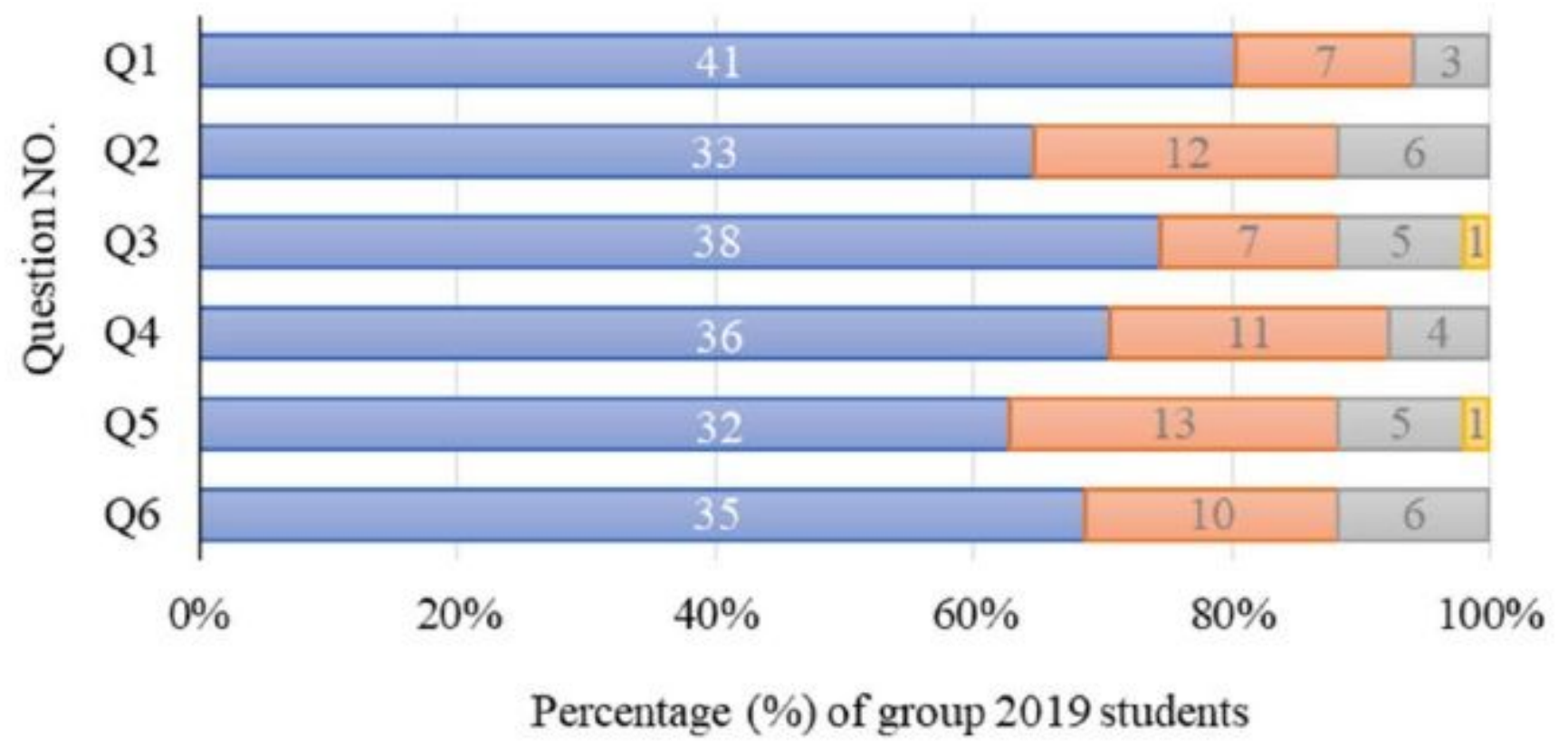

Figure 2

Student feedback to questions based on Likert scale template. The questions are as follows. Q1, The content presented by students in situated learning is correct. Q2, I like the situated learning. Q3, The situated learning helped me understand the blood physiology better. Q4, The situated learning helped me appreciate the importance of principles of blood transfusion. Q5, I hope there will be situated learning in future courses. Q6, I am likely to recommend situated learning to next year's students. 